\title{
Neurochemical and Neuroanatomical Plasticity Following Memory Training and Yoga Interventions in Older Adults with Mild Cognitive Impairment
}

\author{
Hongyu Yang ${ }^{1}$, Amber M. Leaver ${ }^{2}$, Prabha Siddarth ${ }^{1}$, Pattharee Paholpak ${ }^{1,3}$, \\ Linda Ercoli ${ }^{1}$, Natalie M. St. Cyr ${ }^{1}$, Harris A. Eyre ${ }^{1,4,5,6}$, Katherine L. Narr ${ }^{2}$, \\ Dharma S. Khalsa ${ }^{7}$ and Helen Lavretsky ${ }^{1 *}$
}

\begin{abstract}
Semel Institute for Neuroscience and Human Behavior, University of California, Los Angeles (UCLA), Los Angeles, CA, USA ${ }^{2}$ Ahmanson-Lovelace Brain Mapping Center, Department of Neurology, University of California, Los Angeles (UCLA), Los Angeles, CA, USA, ${ }^{3}$ Department of Psychiatry, Faculty of Medicine, Khon Kaen University, Khon Kaen, Thailand, ${ }^{4}$ Discipline of Psychiatry, University of Adelaide, Adelaide, SA, Australia, ${ }^{5}$ MPACT SRC, School of Medicine, Deakin University, Geelong, VIC, Australia, ${ }^{6}$ Department of Psychiatry, University of Melbourne, Melbourne, VIC, Australia, ${ }^{7}$ Alzheimer's Research and Prevention Foundation, Tucson, AZ, USA
\end{abstract}

OPEN ACCESS

Edited by: Ashok Kumar,

University of Florida, USA

Reviewed by:

Adam J. Woods,

University of Florida, USA

Shirley Telles,

Patanjali Research Foundation, India

*Correspondence:

Helen Lavretsky

hlavretsky@mednet.ucla.edu

Received: 05 August 2016 Accepted: 04 November 2016 Published: 21 November 2016

Citation: Yang $H$, Leaver AM, Siddarth $P$, Paholpak P, Ercoli L, St. Cyr NM, Eyre HA, Narr KL, Khalsa DS and Lavretsky H (2016) Neurochemical and Neuroanatomical Plasticity Following Memory Training and Yoga Interventions in Older Adults with Mild Cognitive Impairment.

Front. Aging Neurosci. 8:277. doi: 10.3389/fnagi.2016.00277
Behavioral interventions are becoming increasingly popular approaches to ameliorate age-related cognitive decline, but their underlying neurobiological mechanisms and clinical efficiency have not been fully elucidated. The present study explored brain plasticity associated with two behavioral interventions, memory enhancement training (MET) and a mind-body practice (yogic meditation), in healthy seniors with mild cognitive impairment $(\mathrm{MCl})$ using structural magnetic resonance imaging (s-MRI) and proton magnetic resonance spectroscopy $\left({ }^{1} \mathrm{H}-\mathrm{MRS}\right)$. Senior participants (age $\geq 55$ years) with $\mathrm{MCl}$ were randomized to the MET or yogic meditation interventions. For both interventions, participants completed either MET training or Kundalini Yoga (KY) for 60-min sessions over 12 weeks, with 12-min daily homework assignments. Gray matter volume and metabolite concentrations in the dorsal anterior cingulate cortex (dACC) and bilateral hippocampus were measured by structural MRI and ${ }^{1} \mathrm{H}-\mathrm{MRS}$ at baseline and after 12 weeks of training. Metabolites measured included glutamateglutamine (Glx), choline-containing compounds (Cho, including glycerophosphocholine and phosphocholine), gamma-aminobutyric acid (GABA), and N-acetyl aspartate and $\mathrm{N}$-acetylaspartyl-glutamate (NAA-NAAG). In total, 11 participants completed MET and 14 completed yogic meditation for this study. Structural MRI analysis showed an interaction between time and group in AACC, indicating a trend towards increased gray matter volume after the MET intervention. ${ }^{1} \mathrm{H}-\mathrm{MRS}$ analysis showed an interaction between time and group in choline-containing compounds in bilateral hippocampus, induced by significant decreases after the MET intervention. Though preliminary, our results suggest that memory training induces structural and neurochemical plasticity in seniors with $\mathrm{MCl}$. Further research is needed to determine whether mind-body interventions like yoga yield similar neuroplastic changes.

Keywords: proton magnetic resonance spectroscopy, structural magnetic resonance imaging, memory enhancement training, yogic meditation, dorsal anterior cingulate cortex, hippocampus 


\section{INTRODUCTION}

The global population is aging at a rate unprecedented in human history. About 98 million people will be over 65 years old by 2060 (Mather et al., 2015), which will be paralleled by increased age-related health issues. As a result of the expanding elderly population, cognitive decline and conversion to dementia is becoming an increasingly difficult public health challenge due to high cost of care, morbidity and mortality in patients with Alzheimer's disease (AD; Alzheimer's Association, 2015) and age-related dementia (Hurd et al., 2013). Both neuropsychological and neuroimaging studies have suggested that mild cognitive impairment (MCI) represents a prodromal state leading to degenerative dementias including AD (Petersen et al., 2001; Palmer et al., 2002). Therefore, providing interventions to prevent age-related cognitive decline that are cost-effective and easily accessible may prove an effective way to ensure that both patients and caregivers have better quality of life, while reducing financial burden for families and society.

To date, preventive measures against cognitive decline have mainly focused on pharmacotherapy (Karakaya et al., 2013) and physical exercise (Smith et al., 2010; Behrman and Ebmeier, 2014). Behavioral memory training is also popular, based on the notion that cognition is plastic in older age (Acevedo and Loewenstein, 2007; Eyre et al., 2016). For example, traditional memory training interventions that teach mnemonic techniques involving verbal association and visual imagery and practical strategies have been shown to boost cognitive performance, memory, and quality of life in healthy older adults (Verhaeghen et al., 1992; Jean et al., 2010). Given the growing popularity of online "Brain Training" programs, clearer understanding of behavioral memory training programs already demonstrated to be effective in the clinic is needed.

In recent years, mind-body therapies have also been studied as potential preventive measures for MCI (Grossman et al., 2004). By simultaneously targeting multiple physiological and cognitive processes, as well as their dynamic integration, meditation may offer a more efficient alternative to other behavioral interventions. Indeed, some studies indicate that senior meditators have better memory, perceptual speed, attention and executive functioning compared with non-meditators (Prakash et al., 2012), though results are mixed (Chiesa et al., 2011; Goyal et al., 2014). A combination of Kirtan Kriya (KK) meditation and Kundalini Yoga (KY), as used as an intervention in the current study, is specifically shown to affect physical and mental health outcomes (Shannahoff-Khalsa, 2004; Krisanaprakornkit et al., 2006), including older adults with memory complaints (Moss et al., 2012). Like other forms of mind-body practice, KY and KK have been demonstrated to benefit cognitive function, depressed mood and anxiety, sleep and coping (Black et al., 2013; Lavretsky et al., 2013), including older adults with cognitive impairments (Newberg et al., 2010). Thus, given their effectiveness and ease of use, mind-body interventions like $\mathrm{KY}$ and $\mathrm{KK}$ may be useful tools that can be readily incorporated into future clinical practice.
Despite their promise, the neurobiological mechanisms of behavioral interventions to prevent age-related cognitive decline are not well understood. In the current study, we explored how memory enhancement training (MET) and $\mathrm{KY}+\mathrm{KK}$ yoga affect brain plasticity in two areas of the brain important for memory and cognition, the bilateral hippocampus and dorsal anterior cingulate cortex (dACC). We used structural magnetic resonance imaging (s-MRI) to measure gray-matter volume and proton magnetic resonance spectroscopy $\left({ }^{1} \mathrm{H}\right.$-MRS) to measure brain metabolites. We targeted four metabolite peaks with ${ }^{1} \mathrm{H}$-MRS previously linked to cognitive function (Friedman et al., 1998; Rae et al., 1998; Ross and Sachdev, 2004; Stone, 2009; Yoon et al., 2009), specifically: gamma-aminobutyric acid (GABA) and, Glutamate + Glutamine (Glx), which reflect levels of the major inhibitory and excitatory neurotransmitters, respectively (Maddock and Buonocore, 2012; Ramadan et al., 2013); glycerophosphocholine + phosphocholine (Cho), a marker of cell membrane synthesis and breakdown (Maddock and Buonocore, 2012); and N-acetyl aspartate and N-acetylaspartylglutamate (NAA/NAAG), which is thought to be a marker of neuronal and axonal viability and density (Ross and Sachdev, 2004).

To our knowledge, this project is the first to compare the effects of MET and $\mathrm{KK}+\mathrm{KY}$ on brain structure and neurochemistry in healthy seniors with MCI. Notably, our previous study in this cohort demonstrated that improved verbal memory performance in both MET and $\mathrm{KK}+\mathrm{KY}$ interventions associated with functional neuroplasticity, suggesting yoga and MET may have similar influences on brain function (Eyre et al., 2016). Based on this and related literature indicating reduced brain volume with age and memory disorders (Salat et al., 2004; Lemaitre et al., 2012), we hypothesized that the volume of dACC and bilateral hippocampus would increase after both interventions. Further, we expected that ${ }^{1} \mathrm{H}$-MRS metabolites previously linked with aging and/or memory complaints like choline and NAA/NAAG (Pfefferbaum et al., 1999; Rose et al., 1999) might also change with our interventions. The current study provides further insight into our understanding of the neuroplastic effects of the two interventions, which may help inform future improved, personalized intervention strategies to prevent age-related memory problems and cognitive decline.

\section{MATERIALS AND METHODS}

\section{Participants}

Participants with subjective memory complaints were recruited via advertisements from UCLA outpatient clinics and UCLA Longevity Center Program from 2014 to 2015. Inclusion criteria included: (1) age $\geq 55$ years; (2) a diagnosis of MCI-amnestic type by standard criteria (Petersen, 2004; Winblad et al., 2004) established at a diagnostic consensus conference; (3) Clinical Dementia Rating scale (Morris, 1993) score of 0.5; (4), sufficient English proficiency at the eighth grade or higher reading level as determined by the word reading subtest of the Wide 
Range Achievement Test-4 (Wilkinson and Robertson, 2006) to participate in MET; (5) capacity to provide informed consent. Exclusion criteria included: (1) current or past Axis I psychiatric disorders, or recent unstable medical or neurological disorders; (2) any disabilities preventing participation in the MET or KY $+\mathrm{KK}$ conditions (e.g., severe visual or hearing impairment); (3) insufficient English proficiency; (4) a diagnosis of dementia per the DSM-IV; (5) Mini Mental Health Examination (Folstein et al., 1975) score of 24 or below; (6) psychoactive medications; (7) participation in psychotherapy involving cognitive training. This study was approved by the UCLA Institutional Review Board (IRB). All participants underwent IRB-approved informed consent procedures prior to enrolling in the study.

\section{Clinical Measures}

Participants were assessed at baseline and at 12-weeks (after training). Clinical measurements included the Geriatric Depression Scale (GDS; Yesavage et al., 1983), Cardiovascular Risk Factors (CVRF; Truelsen et al., 1994), and Mini-Mental State Examination (MMSE; Folstein et al., 1975).

\section{Yoga and MET Interventions}

Participants were randomly assigned to either a 60-min weekly MET or KY + KK (yoga) classes. Each group was assigned approximately $12 \mathrm{~min}$ of daily homework specific to the intervention. In total, 25 participants (11 MET and 14 yogic meditation) finished the study.

Memory training (MET) was developed from evidencebased techniques that involve teaching verbal and visual association strategies and other practical strategies to improve memory function. We chose to implement mnemonic methods over computerized memory training programs because the former have a longer history of implementation in aging populations, have been studied more, with much empirical evidence supporting their use in elders.

The KY + KK intervention was conducted by a certified yoga teacher. The KY + KK class included teaching body-movement and mindfulness exercises, specifically: (1) Tuning in (5 min); (2) Warm up (10 min); (3) Pranayam (10 min); (4) Kriya (20 min); (5) Meditation (11 min); and (6) Shavasana (4 min). This standard 12-min KY + KK meditation protocol as created by Yogi Bhajan was taught by the certified yoga teacher. Adverse events were monitored at each visit by using the UKU Side Effect Rating Scale (Lingjaerde et al., 1987).

\section{MRI Acquisition}

Structural MRI (Figure 1) and ${ }^{1} \mathrm{H}-\mathrm{MRS}$ data (Figure 2) were acquired on a 3.0 Tesla TIM Trio scanner (Siemens, Germany) using a 32-channel head coil, and head motion was minimized with the adjacent placement of firm cushions. High resolution motion-corrected multi-echo MPRAGE images were acquired with the following parameters: TR $=2150 \mathrm{~ms}$, TEs $=1.74 / 3.6 / 5.46 / 7.32 \mathrm{~ms}$, TI $=1260 \mathrm{~ms}, \quad \mathrm{FA}=7^{\circ}$, $\mathrm{FOV}=256 \mathrm{~mm} \times 256 \mathrm{~mm}, 176$ sagittal slices, voxel resolution $1.0 \times 1.0 \times 1.0 \mathrm{~mm}^{3}$. These MRI structural images were resliced to position ${ }^{1} \mathrm{H}$-MRS voxels in $\mathrm{dACC}$ $\left(40 \times 30 \times 20 \mathrm{~mm}^{3}\right)$ and bilateral hippocampal gray matter $\left(30 \times 12 \times 12 \mathrm{~mm}^{3}\right.$; see Figures 2 A,B $)$. For the hippocampi, single-voxel point resolved spectroscopy (PRESS) sequences were acquired with the following parameters: $\mathrm{TR}=2200 \mathrm{~ms}$, spectral bandwidth $=1500 \mathrm{~Hz}, \mathrm{TE}=30 \mathrm{~ms}$, and 2048 samples with water suppression yielding 128 averages. For the dACC, a J-edited Mescher-Garwood (MEGA) PRESS sequence available as a Siemens Work-in-progress (WIP) was used (Mescher et al., 1996, 1998), which allowed the detection of GABA concentration with spectral editing: $\mathrm{TR}=2000 \mathrm{~ms}$, spectral bandwidth $=1500 \mathrm{~Hz}$, $\mathrm{TE}=68 \mathrm{~ms}$, and 2048 samples with water suppression yielding 128 averages.

\section{MRI Structure Preprocessing}

FreeSurfer (version 5.1.0, https://surfer.nmr.mgh.harvard.edu/) was used for automated cortical surface reconstruction and cortical/subcortical parcellation estimation on each subject's structural image. Freesurfer morphometric procedures have been demonstrated to show good test-retest reliability across scanner manufacturers and across field strengths (Han et al., 2006; Reuter et al., 2012). The preprocessing outputs were reviewed, manually corrected and reran as necessary by an experienced MRI analyst. The Desikan-Killiany cortical and FreeSurfer subcortical segmentation atlas was used to estimate volume in regions of interest (ROIs; Fischl et al., 2002, 2004) including the bilateral hippocampus and dACC. Total intracranial volume was estimated for inclusion as a covariate in s-MRI statistical analyses.

\section{${ }^{1} \mathbf{H}-M R S$ Preprocessing}

${ }^{1} \mathrm{H}$-MRS metabolite levels were quantified using the LCModel analysis program (Version 6.3; Provencher, 1993; See Figures 2C,D). The MEGA-PRESS sequence acquires two acquisitions, one with the inversion of GABA multiplet at $1.9 \mathrm{ppm}$ and the other without inversion, which allows GABA J-evolution. GABA is detected by subtracting these two spectra. All other metabolites were estimated using non-edited spectra from either the standard PRESS (for hippocampal voxels) or MEGA-PRESS (for dACC) sequences. Basis sets included of NAA-NAAG, Cho, Glx for one basis file, and GABA for another basis file as suggested by LCModel processing. GABA is reported as GABA-to-NAA/NAAG ratio; remaining metabolites are reported as metabolite-to-creatine ratios.

Cramer-Rao metrics were used for quality control. For Glx, metabolite concentrations from data points with Cramer-Rao lower bounds equal to or exceeding $20 \%$ were excluded from analysis. For NAA-NAAG and Cho, Cramer-Rao lower bounds equal to or exceeding $10 \%$ were excluded as these metabolites typically display lower fitting error values. These quality-control criteria led to the exclusions listed below; signal-to-noise (SNR) and full width at half-maximum (FWHM) values are also listed for reference for each metabolite. In dorsal ACC: for GABA, 1 Yoga baseline, 3 Yoga follow-up, 3 MET baseline, 1 MET follow-up were excluded (SNR Mean $\pm \mathrm{SD}=22.21 \pm 9.25$, FWHM Mean $\pm \mathrm{SD}=0.05 \pm 0.01$ ); for Glx, 1 Yoga baseline, 2 Yoga follow-up, 3 MET baseline, 1 MET follow-up 
were excluded (SNR Mean $\pm \mathrm{SD}=24.72 \pm 11.63$, FWHM Mean $\pm \mathrm{SD}=0.06 \pm 0.02$ ); for Cho, 1 Yoga follow-up, 2 MET baseline, 1 MET follow-up were excluded (SNR Mean $\pm \mathrm{SD}=23.65 \pm 11.97$, FWHM Mean $\pm \mathrm{SD}=0.06 \pm 0.02$ ); NAA/NAAG 1 follow-up, 2 MET baseline, 1 MET follow-up were excluded (SNR Mean $\pm \mathrm{SD}=23.65 \pm 11.97$, FWHM Mean $\pm \mathrm{SD}=0.06 \pm 0.02$ ). In bilateral hippocampus: for Glx, 1 Yoga baseline, 1 follow-up, 1 MET follow-up were excluded (SNR Mean $\pm \mathrm{SD}=8.36 \pm 2.46$, FWHM Mean $\pm \mathrm{SD}=0.09 \pm 0.03$ ); for NAA/NAAG 2 Yoga baseline, 1 Yoga follow-up were excluded (SNR Mean $\pm \mathrm{SD}=8.42 \pm 2.42$, FWHM Mean $\pm \mathrm{SD}=0.09 \pm 0.03$ ), for Cho (SNR Mean $\pm \mathrm{SD}=8.23 \pm 2.47$, FWHM Mean $\pm \mathrm{SD}=0.09 \pm 0.04)$.

\section{Statistical Analysis}

For all demographic and clinical measures, the two interventions were compared at baseline by $t$-tests or chi-squared tests. All structural measures and metabolites of interest were analyzed by a mixed effects general linear model (implemented in SAS PROC MIXED), using intervention group, time and the interaction term between time and group as predictors. In analyses of gray-matter volume, total intracranial volume was entered as an additional covariate, and in analyses of hippocampal volume and metabolites, both ROIs were analyzed in the same model with hemisphere (i.e., right and left) entered as an additional within subject factor. Post hoc analyses tested within group changes as well as changes between groups with time. As this is an exploratory study to examine how brain structures and metabolites change due to the interventions, we did not correct for multiple comparisons and significance levels were set at 0.05 , two-tailed.

\section{RESULTS}

\section{Demographic, Clinical and Cognitive Measurements}

Table 1 presents the baseline clinical and demographic characteristics of study participants. The two groups did not

TABLE 1 | Demographic and clinic measures for yoga and memory enhancement training (MET) groups.

\begin{tabular}{lcc}
\hline & Yoga group $(\boldsymbol{n}=\mathbf{1 4})$ & MET group $(\boldsymbol{n}=\mathbf{1 1})$ \\
\hline Age (years) & $67.1(9.5)$ & $67.8(9.7)$ \\
Sex (Female) & $6(42.9 \%)$ & $6(54.5 \%)$ \\
Race (Caucasian) & $12(85.7 \%)$ & $8(72.7 \%)$ \\
Handedness (Right) & $12(85.7 \%)$ & $8(72.7 \%)$ \\
Education & $16.8(1.7)$ & $16.2(1.6)$ \\
BMl & $26.7(4.3)$ & $24.5(3.6)$ \\
MMSE & $28.7(1.3)$ & $29.1(0.7)$ \\
GDS & $7.5(5.1)$ & $5.7(5.6)$ \\
CVRF & $8.3(5.2)$ & $6.6(4.8)$
\end{tabular}

Figures indicate mean with standard deviation (SD), or number with of subjects with percentage (\%) in parentheses. Abbreviations: Education, years of education; BMI, Body Mass Index; MMSE, Mini-Mental Status Exam; GDS, Geriatric Depression Scale; CVRF, Cardiovascular Risk Factor. differ significantly on age, sex, race, handedness, education, Body Mass Index (BMI), MMSE, GDS or CVRF at baseline (all $p>0.2$ ).

\section{MRI Structural Analysis}

We examined gray-matter volume changes after yoga and memory training in bilateral hippocampus and dACC (Table 2 and Figure 1). An effect size (between group Cohen's $d$ ) for gray-matter volume changes (see Table 2) was also calculated. Analyses for the hippocampus did not reveal a significant interaction term between time and group $\left(F_{(1,23)}=1.35, p=0.25\right)$ indicating that change in hippocampal volume did not differ between the two interventions. In dACC, there was a significant interaction term $\left(F_{(1,22)}=4.86, p=0.04\right)$; the memory training group showed a trend towards increased volume after training $\left(t_{(22)}=1.73, p=0.1\right)$ while the yoga group did not show any change $\left(t_{(22)}=1.38, p=0.2\right)$. Further, there were no significant main effects of group or time for either region.

\section{${ }^{1} \mathrm{H}$-MRS Brain Metabolite Analysis}

For ${ }^{1} \mathrm{H}$-MRS analyses, we analyzed Glx, NAA/NAAG, and Cho values, as well as the effect size for the comparisons in bilateral hippocampus and dACC. GABA was also estimated in the dACC using spectral editing as described above (see Table 3 ). In bilateral hippocampus, a significant interaction between time and group was found for choline $\left(F_{(1,38)}=4.35, p=0.04\right.$; See Table 3 and Figure 2). Post hoc analyses showed that choline decreased in the memory training group $\left(t_{(38)}=-2.58, p=0.01\right)$, but did not change in the yoga group $\left(t_{(38)}=0.30, p=0.8\right)$. Of note, though all other measures were similar across treatment groups, hippocampal choline was greater in the memory training group at baseline than the yoga group $\left(t_{(38)}=2.17, p=0.04\right)$. No other metabolites exhibited significant interaction terms, nor were there significant main effects of group or time for any metabolite for the hippocampus. In the dACC, there were no significant interactions or main effects identified for any metabolites.

\section{Correlation Analysis Between MRS, MRI and Clinical Measurements}

We explored whether the changes for clinical measures correlated with the structural or brain chemical changes. None of the correlations between the MRI or MRS changes and GDS or MMSE changes were significant. Note also that followup measures were also reported previously (Eyre et al., 2016); after interventions, GDS Mean(SD) was 3.9(2.5) for Yoga Group and 3.2(2.5) for MET group, and MMSE was 29.0(0.9) for Yoga Group, 29.0(1.0) for MET group.

\section{DISCUSSION}

Taken together, our results suggest that behavioral interventions like MET can impact the anatomy and neurochemistry of the aging brain. In MRI analyses, we found that the MET intervention was associated with decreased choline levels in bilateral hippocampus, as well as modest, but significant increases in gray-matter volume in dACC. This is the first pilot study to evaluate structural and metabolite neuroplasticity 
TABLE 2 | Magnetic resonance imaging (MRI) volumes for yoga and MET groups.

\begin{tabular}{|c|c|c|c|c|c|c|}
\hline \multirow[t]{2}{*}{ Region } & \multicolumn{2}{|c|}{$\begin{array}{c}\text { Yoga group } \\
\text { Mean (SD) }\left(\mathrm{mm}^{3}\right)\end{array}$} & \multicolumn{2}{|c|}{$\begin{array}{c}\text { MET group } \\
\text { Mean (SD) }\left(\mathrm{mm}^{3}\right)\end{array}$} & \multirow[b]{2}{*}{ Time*group } & \multirow[b]{2}{*}{ Effect size } \\
\hline & Baseline & Follow-up & Baseline & Follow-up & & \\
\hline Dorsal anterior cingulate cortex & 2040.8 (363.3) & $2022.0(319.2)$ & $1677.4(239.6)$ & $1716.1(239.9)$ & $F_{(1,23)}=4.9, P=0.04$ & 0.72 \\
\hline Bilateral hippocampus & 3492.7 (477.4) & $3508.6(465.4)$ & $3397.2(321.1)$ & 3438.9 (436.5) & $F_{(1,23)}=1.4, P=0.2$ & 0.08 \\
\hline
\end{tabular}

The reported effect sizes are the between group Cohen's $d$ for changes in MRI volumes.

associated with MET and yoga interventions in seniors with MCI using ${ }^{1} \mathrm{H}$-MRS and s-MRI techniques to our knowledge. However, given our relatively small sample size and the exploratory nature of the study, future research is needed to validate these results, and to determine whether yoga can induce similar patterns of neuroplasticity as we have demonstrated previously with functional MRI (Eyre et al., 2016).

\section{Implications for Increased Hippocampal Choline in Cognitive Aging}

${ }^{1} \mathrm{H}$-MRS is potentially a powerful tool, offering a non-invasive approach to measuring brain metabolites in vivo. In our data, we found that choline in bilateral hippocampus decreased after MET training in seniors with MCI. Choline is a common target in ${ }^{1} \mathrm{H}$-MRS studies, and its peak reflects the presence of phosphorylcholine and glycerophosphoryl-choline. These choline-containing compounds play significant roles in synthesis and breakdown of lipid components of cell membranes, and as precursors for the neurotransmitter acetylcholine (Amenta and Tayebati, 2008). Choline levels measured with ${ }^{1} \mathrm{H}$-MRS have been demonstrated to increase in the aging brain (Pfefferbaum et al., 1999; Haga et al., 2009) and in AD (Pfefferbaum et al., 1999; Kantarci et al., 2000, 2007). Specifically, regarding ${ }^{1} \mathrm{H}-\mathrm{MRS}$ in the hippocampus and medial temporal cortex, studies have reported increased choline with age in humans (Angelie et al., 2001) and in animal models (Katz-Brull et al., 2002), though results are mixed (Haga et al., 2009) and hippocampal choline may not be elevated in MCI when compared to healthy seniors (Tumati et al., 2013). However, studies using more sensitive and invasive techniques to measure choline are more consistent; choline and choline-containing compounds measured directly from CSF via lumbar puncture seem to be consistently elevated in AD (Elble et al., 1989;

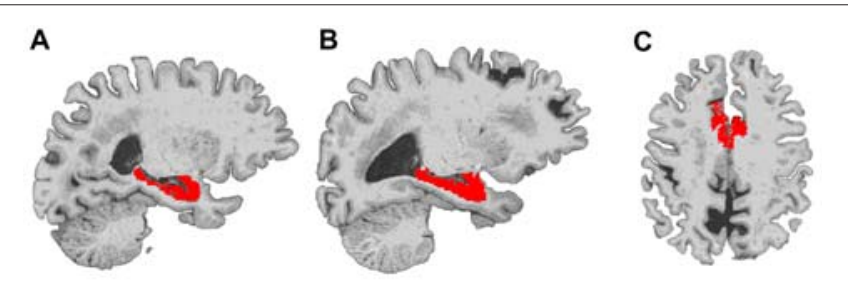

FIGURE 1 | Example locations of bilateral hippocampus and dorsal anterior cingulate cortex (dACC) regions used in Freesurfer volume analyses. The right hippocampus (A), left hippocampus (B) and dorsal ACC (C) are displayed in red on a representative subject's brain image.
Walter et al., 2004; Ibáñez et al., 2012) and MCI (Ibáñez et al., 2012). Thus, our results may suggest that behavioral interventions like MET can reduce age-related choline increases in the hippocampus. The mechanisms underlying these effects cannot be addressed directly with MRI; however, future studies will be better able to determine, for example, whether these changes in choline-containing compounds relate to membrane turnover, acetylcholine synthesis, or other factors (Ibáñez et al., 2012).

Medial temporal lobe structures like the hippocampus are critical brain regions involved in memory (Tulving and Markowitsch, 1998). Hippocampal volume is often linked to performance on memory tasks (Schultz et al., 2015), and has also been consistently demonstrated to change with memory training and intervention (Erickson et al., 2011). Hippocampal volume is also known to decrease with age and in association with $\mathrm{MCI}, \mathrm{AD}$ and other age-related disorders (Lupien et al., 1998; Elcombe et al., 2015). Given that cholinecontaining compounds measured with ${ }^{1} \mathrm{H}$-MRS are associated with cell-membrane turnover, one might expect corresponding structural changes in the hippocampus as well; however, we did not find a link between hippocampal volume and memory training in the current study. This could be due to our relatively small sample, relatively short training time, and/or other aspects of our methodological approach. For example, some studies have indicated that structural plasticity in the hippocampus might vary across hippocampal subfields in relation to memory interventions (Engvig et al., 2012) and $\mathrm{AD}$ status (Mueller et al., 2007). Clearly, more work is needed to determine the relationship between structural plasticity in the hippocampus and behavioral interventions for age-related memory complaints.

\section{Role of Anterior Cingulate Cortex in Cognitive Aging}

In our study, we provide novel evidence that a behavioral memory intervention (MET) can modestly increase cortical gray matter in dACC, a region of the brain linked to multiple key cognitive functions, such as error detection (Gehring et al., 1993), and executive processing (Carter et al., 2000). Gray-matter volume has been demonstrated to decrease with age in the ACC in both cross-sectional (Sowell et al., 2003) and longitudinal studies (Resnick et al., 2003). Correspondingly, age is negatively correlated with blood flow in dorsal and rostral ACC regions (Vaidya et al., 2007). Seniors who engage more in cognitive games and puzzles in their daily lives also tend to have 
TABLE 3 | Proton magnetic resonance spectroscopy ( $\left.{ }^{1} \mathrm{H}-\mathrm{MRS}\right)$ signal intensity ratio measures for yoga and MET groups.

\begin{tabular}{|c|c|c|c|c|c|c|}
\hline & \multicolumn{2}{|c|}{$\begin{array}{l}\text { Yoga group } \\
\text { Mean (SD) }\end{array}$} & \multicolumn{2}{|c|}{$\begin{array}{l}\text { MET group } \\
\text { Mean (SD) }\end{array}$} & \multirow[b]{2}{*}{ Time* group } & \multirow[b]{2}{*}{ Effect size } \\
\hline & Baseline & Follow-up & Baseline & Follow-up & & \\
\hline \multicolumn{7}{|l|}{ Dorsal ACC } \\
\hline GABA & $0.35(0.18)$ & $0.33(0.17)$ & $0.35(0.20)$ & $0.31(0.14)$ & $F_{(1,17)}=0.07, P=0.8$ & 0.44 \\
\hline Glx & $0.74(0.22)$ & $0.94(0.48)$ & $0.99(0.59)$ & $1.26(1.24)$ & $F_{(1,17)}=0.67, P=0.4$ & 0.62 \\
\hline Cho & $0.27(0.07)$ & $0.26(0.04)$ & $0.25(0.03)$ & $0.26(0.05)$ & $F_{(1,19)}=0.51, P=0.5$ & 0.41 \\
\hline NAA/NAAG & $1.21(0.17)$ & $1.24(0.18)$ & $1.30(0.15)$ & $1.28(0.11)$ & $F_{(1,19)}=0.24, P=0.6$ & 0.06 \\
\hline \multicolumn{7}{|c|}{ Bilateral hippocampus } \\
\hline Glx & $1.77(0.35)$ & $1.83(0.37)$ & $1.72(0.35)$ & $1.88(0.46)$ & $F_{(1,40)}=0.33, P=0.6$ & 0.18 \\
\hline Cho & $0.31(0.04)$ & $0.32(0.03)$ & $0.34(0.05)$ & $0.31(0.04)$ & $F_{(1,38)}=4.35, P=0.04$ & 0.42 \\
\hline NAA/NAAG & $1.17(0.11)$ & $1.10(0.12)$ & $1.14(0.13)$ & $1.17(0.19)$ & $F_{(1,40)}=2.90, P=0.09$ & 1.02 \\
\hline
\end{tabular}

The reported effect sizes are the between group Cohen's d for changes in MRS signal intensity measures. Signal intensity measures were obtained by the ratio of creatine and phosphocreatine ( $\mathrm{Cr}+\mathrm{PCr}$ ) except gamma-aminobutyric acid (GABA) by the ratio of N-acetyl aspartate and N-acetylaspartyl-glutamate (NAA/NAAG). Abbreviations: Dorsal ACC, Dorsal anterior cingulate cortex; Gix, Glutamate + Glutamine; Cho, glycerophosphocholine + phosphocholine.

greater ACC gray matter volume (Schultz et al., 2015), which is consistent with our results and raises the possibility that engaging in cognitive-behavioral games or training could prevent age-related structural atrophy in this region. Indeed, a recent study indicated a trend towards increased rostral ACC thickness in seniors after MET; however, this effect did not survive a stringent validation analysis (Engvig et al., 2010). Although our effects are modest, they do indicate that participating in effective behavioral interventions may help to ameliorate age-related brain changes associated with poor memory and cognitive performance.

\section{Yoga and the Aging Brain}

Structural plasticity in the dACC and hippocampus has also been associated with yoga practice in previous studies; however, we did not find evidence of gray-matter volume changes in dACC or hippocampus after our 12-week yoga intervention. Yoga has been linked to anatomical changes in frontal cortex (Baijal and Srinivasan, 2010; Froeliger et al., 2012; Villemure et al., 2014; Desai et al., 2015), anterior cingulate cortex (ACC) and insula (Nakata et al., 2014; Villemure et al., 2014, 2015), and the hippocampus (Froeliger et al., 2012; Villemure et al., 2015). However, many of these studies compare the brains of
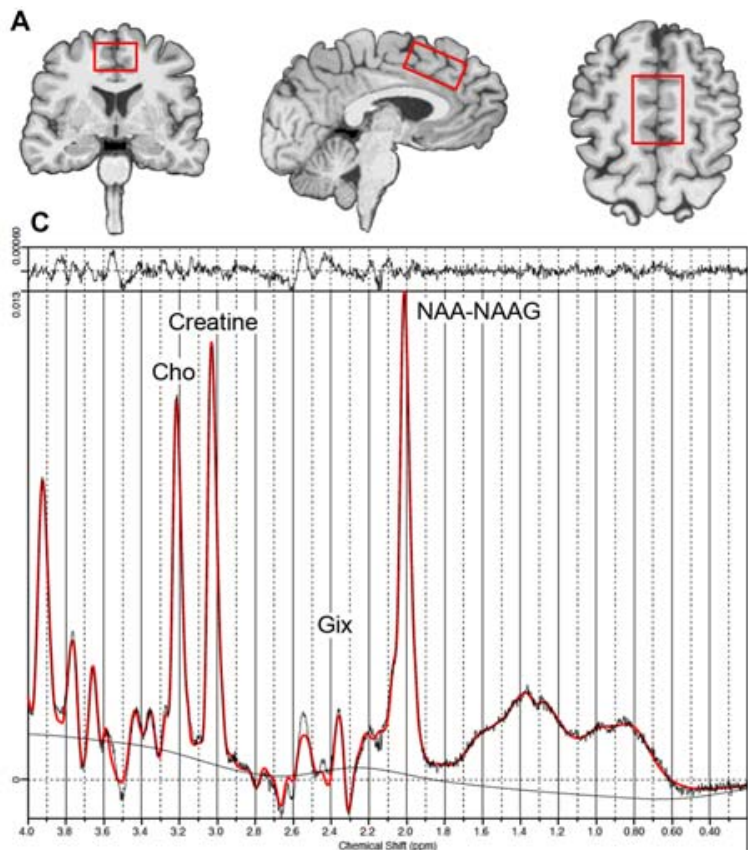

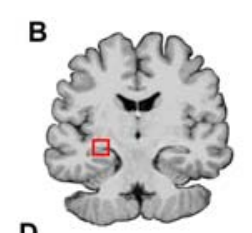

D
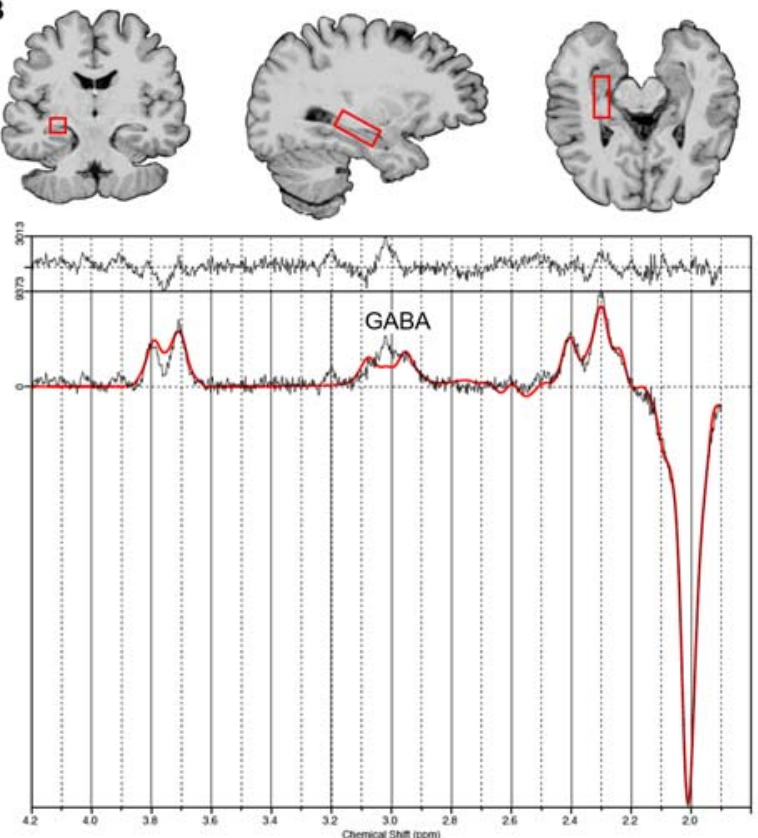

FIGURE 2 | Example voxel placement for the dorsal ACC (A), right hippocampus (B, voxel location for the left hippocampus is similar to the right) and example LC model processing output for the non-edited (C) and edited difference spectra (D). Creatine, Phosphocreatine + Creatine; Glx, glutamate+ glutamine; Cho, glycerophosphocholine + phosphocholine; NAA-NAAG, N-acetyl aspartate + N-acetylaspartyl-glutamate; GABA, $\gamma$-Aminobutyric acid. 
practiced yogis with several months or years of experience to yoga-naive controls (Froeliger et al., 2012); perhaps the relatively shorter length of training in the current study (12 weeks) was less conducive to detecting structural plasticity associated with our yoga intervention. In this same cohort, we have already demonstrated that memory improvements after yoga and MET may induce functional plasticity in similar brain regions (Eyre et al., 2016).

\section{Limitations}

As with all research, there are limitations one should consider when interpreting the results of the current study. Our relatively small sample size and short duration of yogic meditation and memory trainings may have compromised our power to detect significant effects. This may have also played a role in our finding indicating that the yoga and MET groups differed in hippocampal choline at baseline; incidental findings like these are a challenge accompanying pilot studies like ours. Future studies (Flak et al., 2014) with larger sample sizes will provide critical independent validation of our results. However, despite these limitations we did detect two significant and potentially biologically meaningful effects, which may be generalizable to a broad population of seniors with MCI given that both intervention groups were matched for demographic features. The current study did not include a placebo or period without an intervention as a control condition, or a group of healthy seniors without MCI, which means that we are unable to directly compare our findings with neuroplasticity that might occur with typical aging similar time windows (i.e., 12 weeks). We also targeted structural and metabolite changes using ${ }^{1} \mathrm{H}$-MRS and s-MRI; future studies integrating across more and different MRI modalities may be better able to examine different aspects of brain plasticity occurring after behavioral interventions like yoga and MET. Notably, GABA, which has a relatively low

\section{REFERENCES}

Acevedo, A., and Loewenstein, D. A. (2007). Nonpharmacological cognitive interventions in aging and dementia. J. Geriatr. Psychiatry Neurol. 20, 239-249. doi: 10.1177/0891988707308808

Amenta, F., and Tayebati, S. K. (2008). Pathways of acetylcholine synthesis, transport and release as targets for treatment of adult-onset cognitive dysfunction. Curr. Med. Chem. 15, 488-498. doi: 10.2174/092986708783 503203

Angelie, E., Bonmartin, A., Boudraa, A., Gonnaud, P. M., Mallet, J. J., and SappeyMarinier, D. (2001). Regional differences and metabolic changes in normal aging of the human brain: proton MR spectroscopic imaging study. Am. J. Neuroradiol. 22, 119-127.

Alzheimer's Association. (2015). 2015 Alzheimer's disease facts and figures. Alzheimers Dement. 11, 332-384. doi: 10.1016/j.jalz.2015.02.003

Baijal, S., and Srinivasan, N. (2010). Theta activity and meditative states: spectral changes during concentrative meditation. Cogn. Process. 11, 31-38. doi: 10. 1007/s10339-009-0272-0

Behrman, S., and Ebmeier, K. P. (2014). Can exercise prevent cognitive decline? Practitioner 258, 17-21, 12-13.

Black, D. S., Cole, S. W., Irwin, M. R., Breen, E., St Cyr, N. M., Nazarian, N., et al. (2013). Yogic meditation reverses NF- $\mathrm{B}$ and IRF-related transcriptome dynamics in leukocytes of family dementia caregivers in a randomized controlled trial. Psychoneuroendocrinology 38, 348-355. doi: 10.1016/j. psyneuen.2012.06.011 concentration in the brain, was only sampled in the AACC given that the voxel size for the hippocampus was considered too small to achieve the required SNR. In spite of these possible limitations, this study is a promising start to elucidating the brain mechanisms of behavioral interventions for seniors with MCI.

\section{Conclusion}

The present study examined changes in brain metabolites and structure among individuals undergoing memory training and yogic meditation. We demonstrated that memory training over 3 months is associated with decreased choline levels in bilateral hippocampus and increased gray-matter volume in dACC, suggesting that behavioral interventions like MET may ameliorate markers of brain aging. These effects are somewhat modest, and would benefit from independent validation in larger samples and perhaps over longer-duration interventions. However, these findings suggest that engaging in cognitive activities and mind-body practices may affect the brain in positive ways, and may be combined as part of a multi-faceted approach to encourage healthy aging.

\section{AUTHOR CONTRIBUTIONS}

HL, KLN, DSK, LE and PS designed the research; HY, NMSC and HL performed the research; HY, AML and PS analyzed the data; and HY, AML, PS, PP, HAE, KLN and HL wrote the article.

\section{FUNDING}

This study was supported by the Alzheimer's Research and Prevention Foundation (ARPF), and 2014 National Alliance for Research on Schizophrenia and Depression (NARSAD) Young Investigator Grant from the Brain and Behavior Research Foundation (22325).
Carter, C. S., Macdonald, A. M., Botvinick, M., Ross, L. L., Stenger, V. A., Noll, D., et al. (2000). Parsing executive processes: strategic vs. evaluative functions of the anterior cingulate cortex. Proc. Natl. Acad. Sci. U S A 97, 1944-1948. doi: 10. 1073/pnas.97.4.1944

Chiesa, A., Calati, R., and Serretti, A. (2011). Does mindfulness training improve cognitive abilities? A systematic review of neuropsychological findings. Clin. Psychol. Rev. 31, 449-464. doi: 10.1016/j.cpr.2010.11.003

Desai, R., Tailor, A., and Bhatt, T. (2015). Effects of yoga on brain waves and structural activation: a review. Complement. Ther. Clin. Pract. 21, 112-118. doi: 10.1016/j.ctcp.2015.02.002

Elble, R., Giacobini, E., and Higgins, C. (1989). Choline levels are increased in cerebrospinal fluid of Alzheimer patients. Neurobiol. Aging 10, 45-50. doi: 10. 1016/s0197-4580(89)80009-0

Elcombe, E. L., Lagopoulos, J., Duffy, S. L., Lewis, S. J. G., Norrie, L., Hickie, I. B., et al. (2015). Hippocampal volume in older adults at risk of cognitive decline: the role of sleep, vascular risk, and depression. J. Alzheimers Dis. 44, 1279-1290. doi: 10.3233/JAD-142016

Engvig, A., Fjell, A. M., Westlye, L. T., Moberget, T., Sundseth, Ø., Larsen, V. A., et al. (2010). Effects of memory training on cortical thickness in the elderly. Neuroimage 52, 1667-1676. doi: 10.1016/j.neuroimage.2010. 05.041

Engvig, A., Fjell, A. M., Westlye, L. T., Skaane, N. V., Sundseth, Ø., and Walhovd, K. B. (2012). Hippocampal subfield volumes correlate with memory training benefit in subjective memory impairment. Neuroimage 61, 188-194. doi: 10.1016/j.neuroimage.2012.02.072 
Erickson, K. I., Voss, M. W., Prakash, R. S., Basak, C., Szabo, A., Chaddock, L., et al. (2011). Exercise training increases size of hippocampus and improves memory. Proc. Natl. Acad. Sci. U S A 108, 3017-3022. doi: 10.1073/pnas.1015950108

Eyre, H. A., Acevedo, B., Yang, H., Siddarth, P., Van Dyk, K., Ercoli, L., et al. (2016). Changes in neural connectivity and memory following a yoga intervention for older adults: a pilot study. J. Alzheimers Dis. 52, 673-684. doi: 10.3233/JAD-150653

Fischl, B., Salat, D. H., Busa, E., Albert, M., Dieterich, M., Haselgrove, C., et al. (2002). Whole brain segmentation: automated labeling of neuroanatomical structures in the human brain. Neuron 33, 341-355. doi: 10.1016/S08966273(02)00569-X

Fischl, B., van der Kouwe, A., Destrieux, C., Halgren, E., Ségonne, F., Salat, D. H., et al. (2004). Automatically parcellating the human cerebral cortex. Cereb. Cortex 14, 11-22. doi: 10.1093/cercor/bhg087

Flak, M. M., Hernes, S. S., Chang, L., Ernst, T., Douet, V., Skranes, J., et al. (2014). The Memory Aid study: protocol for a randomized controlled clinical trial evaluating the effect of computer-based working memory training in elderly patients with mild cognitive impairment (MCI). Trials 15:156. doi: 10. 1186/1745-6215-15-156

Folstein, M. F., Folstein, S. E., and McHugh, P. R. (1975). "Mini-mental state". A practical method for grading the cognitive state of patients for the clinician. J. Psychiatr. Res. 12, 189-198. doi: 10.1016/0022-3956(75)90026-6

Friedman, S. D., Brooks, W. M., Jung, R. E., Hart, B. L., and Yeo, R. A. (1998). Proton MR spectroscopic findings correspond to neuropsychological function in traumatic brain injury. Am. J. Neuroradiol. 19, 1879-1885.

Froeliger, B., Garland, E. L., and McClernon, F. J. (2012). Yoga meditation practitioners exhibit greater gray matter volume and fewer reported cognitive failures: results of a preliminary voxel-based morphometric analysis. Evid. Based Complement. Alternat. Med. 2012:821307. doi: 10.1155/2012/821307

Gehring, W. J., Goss, B., Coles, M. G. H., Meyer, D. E., and Donchin, E. (1993). A neural system for error detection and compensation. Psychol. Sci. 4, 385-390. doi: 10.1111/j.1467-9280.1993.tb00586.x

Goyal, M., Singh, S., Sibinga, E. M., Gould, N. F., Rowland-Seymour, A., Sharma, R., et al. (2014). Meditation programs for psychological stress and wellbeing: a systematic review and meta-analysis. JAMA Intern. Med. 174, 357-368. doi: 10.1001/jamainternmed.2013.13018

Grossman, P., Niemann, L., Schmidt, S., and Walach, H. (2004). Mindfulnessbased stress reduction and health benefits. A meta-analysis. J. Psychosom. Res. 57, 35-43. doi: 10.1016/S0022-3999(03)00573-7

Haga, K. K., Khor, Y. P., Farrall, A., and Wardlaw, J. M. (2009). A systematic review of brain metabolite changes, measured with $1 \mathrm{H}$ magnetic resonance spectroscopy, in healthy aging. Neurobiol. Aging 30, 353-363. doi: 10.1016/j. neurobiolaging.2007.07.005

Han, X., Jovicich, J., Salat, D., van der Kouwe, A., Quinn, B., Czanner, S., et al. (2006). Reliability of MRI-derived measurements of human cerebral cortical thickness: the effects of field strength, scanner upgrade and manufacturer. Neuroimage 32, 180-194. doi: 10.1016/j.neuroimage.2006. 02.051

Hurd, M. D., Martorell, P., Delavande, A., Mullen, K. J., and Langa, K. M. (2013). Monetary costs of dementia in the United States. N. Engl. J. Med. 368, 1326-1334. doi: 10.1056/NEJMsa1204629

Ibáñez, C., Simó, C., Martín-Álvarez, P. J., Kivipelto, M., Winblad, B., CedazoMínguez, A., et al. (2012). Toward a predictive model of Alzheimer's disease progression using capillary electrophoresis-mass spectrometry metabolomics. Anal. Chem. 84, 8532-8540. doi: 10.1021/ac301243k

Jean, L., Bergeron, M. E., Thivierge, S., and Simard, M. (2010). Cognitive intervention programs for individuals with mild cognitive impairment: systematic review of the literature. Am. J. Geriatr. Psychiatry 18, 281-296. doi: 10.1097/JGP.0b013e3181c37ce9

Kantarci, K., Jack, C. R. Jr., Xu, Y. C., Campeau, N. G., O'Brien, P. C., Smith, G. E., et al. (2000). Regional metabolic patterns in mild cognitive impairment and Alzheimer's disease: a 1H MRS study. Neurology 55, 210-217. doi: 10. 1212/WNL.55.2.210

Kantarci, K., Weigand, S. D., Petersen, R. C., Boeve, B. F., Knopman, D. S., Gunter, J., et al. (2007). Longitudinal $1 \mathrm{H}$ MRS changes in mild cognitive impairment and Alzheimer's disease. Neurobiol. Aging 28, 1330-1339. doi: 10. 1016/j.neurobiolaging.2006.06.018

Karakaya, T., Fußer, F., Schröder, J., and Pantel, J. (2013). Pharmacological treatment of mild cognitive impairment as a prodromal syndrome of Alzheimer's disease. Curr. Neuropharmacol. 11, 102-108. doi: 10. 2174/1570159x11311010012

Katz-Brull, R., Koudinov, A. R., and Degani, H. (2002). Choline in the aging brain. Brain Res. 951, 158-165. doi: 10.1016/s0006-8993(02)03155-4

Krisanaprakornkit, T., Krisanaprakornkit, W., Piyavhatkul, N., and Laopaiboon, M. (2006). Meditation therapy for anxiety disorders. Cochrane Database Syst. Rev. 1:CD004998. doi: 10.1002/14651858. CD004998

Lavretsky, H., Epel, E. S., Siddarth, P., Nazarian, N., Cyr, N. S., Khalsa, D. S., et al. (2013). A pilot study of yogic meditation for family dementia caregivers with depressive symptoms: effects on mental health, cognition and telomerase activity. Int. J. Geriatr. Psychiatry 28, 57-65. doi: 10.1002/gps.3790

Lemaitre, H., Goldman, A. L., Sambataro, F., Verchinski, B. A., MeyerLindenberg, A., Weinberger, D. R., et al. (2012). Normal age-related brain morphometric changes: nonuniformity across cortical thickness, surface area and gray matter volume? Neurobiol. Aging 33, 617.e1-617.e9. doi: 10.1016/j. neurobiolaging.2010.07.013

Lingjaerde, O., Ahlfors, U. G., Bech, P., Dencker, S. J., and Elgen, K. (1987). The UKU side effect rating scale. A new comprehensive rating scale for psychotropic drugs and a cross-sectional study of side effects in neuroleptictreated patients. Acta Psychiatr. Scand. Suppl. 334, 1-100. doi: 10.1111/j.16000447.1987.tb10566.x

Lupien, S. J., de Leon, M., de Santi, S., Convit, A., Tarshish, C., Nair, N. P., et al. (1998). Cortisol levels during human aging predict hippocampal atrophy and memory deficits. Nat. Neurosci. 1, 69-73. doi: 10.1038/271

Maddock, R. J., and Buonocore, M. H. (2012). MR spectroscopic studies of the brain in psychiatric disorders. Curr. Top. Behav. Neurosci. 11, 199-251. doi: 10 1007/7854_2011_197

Mather, M., Jacobsen, L. A., and Pollard, K. M. (2015). Aging in the united states. Popul. Bull. 70, 1-23.

Mescher, M., Merkle, H., Kirsch, J., Garwood, M., and Gruetter, R. (1998). Simultaneous in vivo spectral editing and water suppression. NMR Biomed. 11, 266-272. doi: 10.1002/(SICI)1099-1492(199810)11:6<266::AIDNBM530>3.0.CO;2-J

Mescher, M., Tannus, A., O'neil Johnson, M., and Garwood, M. (1996). Solvent suppression using selective echo dephasing. J. Magn. Reson. A 123, 226-229. doi: 10.1006/jmra.1996.0242

Morris, J. C. (1993). The Clinical Dementia Rating (CDR): current version and scoring rules. Neurology 43, 2412-2414. doi: 10.1212/wnl.43.11. $2412-\mathrm{a}$

Moss, A. S., Wintering, N., Roggenkamp, H., Khalsa, D. S., Waldman, M. R., Monti, D., et al. (2012). Effects of an 8-week meditation program on mood and anxiety in patients with memory loss. J. Altern. Complement. Med. 18, 48-53. doi: $10.1089 / \mathrm{acm} .2011 .0051$

Mueller, S. G., Stables, L., Du, A. T., Schuff, N., Truran, D., Cashdollar, N., et al. (2007). Measurement of hippocampal subfields and age-related changes with high resolution MRI at 4T. Neurobiol. Aging 28, 719-726. doi: 10.1016/j. neurobiolaging.2006.03.007

Nakata, H., Sakamoto, K., and Kakigi, R. (2014). Meditation reduces pain-related neural activity in the anterior cingulate cortex, insula, secondary somatosensory cortex and thalamus. Front. Psychol. 5:1489. doi: 10.3389/fpsyg.2014. 01489

Newberg, A. B., Wintering, N., Khalsa, D. S., Roggenkamp, H., and Waldman, M. R. (2010). Meditation effects on cognitive function and cerebral blood flow in subjects with memory loss: a preliminary study. J. Alzheimers Dis. 20, 517-526. doi: 10.3233/JAD-2010-1391

Palmer, K., Wang, H. X., Bäckman, L., Winblad, B., and Fratiglioni, L. (2002). Differential evolution of cognitive impairment in nondemented older persons: results from the Kungsholmen Project. Am. J. Psychiatry 159, 436-442. doi: 10. 1176/appi.ajp.159.3.436

Petersen, R. C. (2004). Mild cognitive impairment as a diagnostic entity. J. Intern. Med. 256, 183-194. doi: 10.1111/j.1365-2796.2004.01388.x

Petersen, R. C., Doody, R., Kurz, A., Mohs, R. C., Morris, J. C., Rabins, P. V. et al. (2001). Current concepts in mild cognitive impairment. Arch. Neurol. 58, 1985-1992. doi: 10.1001/archneur.58.12.1985

Pfefferbaum, A., Adalsteinsson, E., Spielman, D., Sullivan, E. V., and Lim, K. O. (1999). in vivo brain concentrations of $\mathrm{N}$-acetyl compounds, creatine and choline in Alzheimer disease. Arch. Gen. Psychiatry 56, 185-192. doi: 10. 1001/archpsyc.56.2.185 
Prakash, R., Rastogi, P., Dubey, I., Abhishek, P., Chaudhury, S., and Small, B. J. (2012). Long-term concentrative meditation and cognitive performance among older adults. Neuropsychol. Dev. Cogn. B Aging Neuropsychol. Cogn. 19, 479-494. doi: 10.1080/13825585.2011.630932

Provencher, S. W. (1993). Estimation of metabolite concentrations from localized in vivo proton NMR spectra. Magn. Reson. Med. 30, 672-679. doi: 10. 1002/mrm.1910300604

Rae, C., Lee, M. A., Dixon, R. M., Blamire, A. M., Thompson, C. H., Styles, P., et al. (1998). Metabolic abnormalities in developmental dyslexia detected by $1 \mathrm{H}$ magnetic resonance spectroscopy. Lancet 351, 1849-1852. doi: 10.1016/s01406736(97)99001-2

Ramadan, S., Lin, A., and Stanwell, P. (2013). Glutamate and glutamine: a review of in vivo MRS in the human brain. NMR Biomed. 26, 1630-1646. doi: 10. 1002/nbm.3045

Resnick, S. M., Pham, D. L., Kraut, M. A., Zonderman, A. B., and Davatzikos, C. (2003). Longitudinal magnetic resonance imaging studies of older adults: a shrinking brain. J. Neurosci. 23, 3295-3301.

Reuter, M., Schmansky, N. J., Rosas, H. D., and Fischl, B. (2012). Within-subject template estimation for unbiased longitudinal image analysis. Neuroimage 61, 1402-1418. doi: 10.1016/j.neuroimage.2012.02.084

Rose, S. E., de Zubicaray, G. I., Wang, D., Galloway, G. J., Chalk, J. B., Eagle, S. C., et al. (1999). A $1 \mathrm{H}$ MRS study of probable Alzheimer's disease and normal aging: implications for longitudinal monitoring of dementia progression. Magn. Reson. Imaging 17, 291-299. doi: 10.1016/s0730-725x(98)00168-4

Ross, A. J., and Sachdev, P. S. (2004). Magnetic resonance spectroscopy in cognitive research. Brain Res. Rev. 44, 83-102. doi: 10.1016/j.brainresrev.2003. 11.001

Salat, D. H., Buckner, R. L., Snyder, A. Z., Greve, D. N., Desikan, R. S., Busa, E., et al. (2004). Thinning of the cerebral cortex in aging. Cereb. Cortex 14, 721-730. doi: 10.1093/cercor/bhh032

Schultz, S. A., Larson, J., Oh, J., Koscik, R., Dowling, M. N., Gallagher, C. L., et al. (2015). Participation in cognitively-stimulating activities is associated with brain structure and cognitive function in preclinical Alzheimer's disease. Brain Imaging Behav. 9, 729-736. doi: 10.1007/s11682-014-9329-5

Shannahoff-Khalsa, D. S. (2004). An introduction to Kundalini yoga meditation techniques that are specific for the treatment of psychiatric disorders. J. Altern. Complement. Med. 10, 91-101. doi: 10.1089/107555304322849011

Smith, P. J., Blumenthal, J. A., Hoffman, B. M., Cooper, H., Strauman, T. A., Welsh-Bohmer, K., et al. (2010). Aerobic exercise and neurocognitive performance: a meta-analytic review of randomized controlled trials. Psychosom. Med. 72, 239-252. doi: 10.1097/PSY.0b013e3181d14633

Sowell, E. R., Peterson, B. S., Thompson, P. M., Welcome, S. E., Henkenius, A. L., and Toga, A. W. (2003). Mapping cortical change across the human life span. Nat. Neurosci. 6, 309-315. doi: 10.1038/nn1008

Stone, J. M. (2009). Imaging the glutamate system in humans: relevance to drug discovery for schizophrenia. Curr. Pharm. Des. 15, 2594-2602. doi: 10. 2174/138161209788957438

Truelsen, T., Lindenstrøm, E., and Boysen, G. (1994). Comparison of probability of stroke between the copenhagen city heart study and the framingham study. Stroke 25, 802-807. doi: 10.1161/01.str.25.4.802

Tulving, E., and Markowitsch, H. J. (1998). Episodic and declarative memory: role of the hippocampus. Hippocampus 8, 198-204. doi: 10.1002/(SICI)10981063(1998)8:3<198::AID-HIPO2 > 3.3.CO;2-J
Tumati, S., Martens, S., and Aleman, A. (2013). Magnetic resonance spectroscopy in mild cognitive impairment: systematic review and meta-analysis. Neurosci. Biobehav. Rev. 37, 2571-2586. doi: 10.1016/j.neubiorev.2013.08.004

Vaidya, J. G., Paradiso, S., Boles Ponto, L. L., McCormick, L. M., and Robinson, R. G. (2007). Aging, grey matter and blood flow in the anterior cingulate cortex. Neuroimage 37, 1346-1353. doi: 10.1016/j.neuroimage.2007. 06.015

Verhaeghen, P., Marcoen, A., and Goossens, L. (1992). Improving memory performance in the aged through mnemonic training: a meta-analytic study. Psychol. Aging 7, 242-251. doi: 10.1037/0882-7974.7.2.242

Villemure, C., Čeko, M., Cotton, V. A., and Bushnell, M. C. (2014). Insular cortex mediates increased pain tolerance in yoga practitioners. Cereb. Cortex 24, 2732-2740. doi: 10.1093/cercor/bht124

Villemure, C., Čeko, M., Cotton, V. A., and Bushnell, M. C. (2015). Neuroprotective effects of yoga practice: age-, experience- and frequencydependent plasticity. Front. Hum. Neurosci. 9:281. doi: 10.3389/fnhum.2015. 00281

Walter, A., Korth, U., Hilgert, M., Hartmann, J., Weichel, O., Hilgert, M., et al. (2004). Glycerophosphocholine is elevated in cerebrospinal fluid of Alzheimer patients. Neurobiol. Aging 25, 1299-1303. doi: 10.1016/j.neurobiolaging.2004. 02.016

Wilkinson, G. S., and Robertson, G. J. (2006). Wide Range Achievement Test 4 Professional Manual. Lutz, FL: Psychological Assessment Resources.

Winblad, B., Palmer, K., Kivipelto, M., Jelic, V., Fratiglioni, L., Wahlund, L. O., et al. (2004). Mild cognitive impairment-beyond controversies, towards a consensus: report of the International Working Group on Mild Cognitive Impairment. J. Intern. Med. 256, 240-246. doi: 10.1111/j.1365-2796.2004. 01380.x

Yesavage, J. A., Brink, T. L., Rose, T. L., Lum, O., Huang, V., Adey, M., et al. (1983). Development and validation of a geriatric depression screening scale: a preliminary report. J. Psychiatr. Res. 17, 37-49. doi: 10.1016/00223956(82)90033-4

Yoon, J. H., Rokem, A. S., Silver, M. A., Minzenberg, M. J., Ursu, S., Ragland, J. D., et al. (2009). Diminished orientation-specific surround suppression of visual processing in schizophrenia. Schizophr. Bull. 35, 1078-1084. doi: 10. 1093/schbul/sbp064

Conflict of Interest Statement: The authors declare that the research was conducted in the absence of any commercial or financial relationships that could be construed as a potential conflict of interest.

The reviewer AJW and handling Editor declared their shared affiliation, and the handling Editor states that the process nevertheless met the standards of a fair and objective review.

Copyright (c) 2016 Yang, Leaver, Siddarth, Paholpak, Ercoli, St. Cyr, Eyre, Narr, Khalsa and Lavretsky. This is an open-access article distributed under the terms of the Creative Commons Attribution License (CC BY). The use, distribution and reproduction in other forums is permitted, provided the original author(s) or licensor are credited and that the original publication in this journal is cited, in accordance with accepted academic practice. No use, distribution or reproduction is permitted which does not comply with these terms. 